\title{
A 3-D Mathematical Model of Thermal Field Evolution in the Direct Chill Casting of Superlight Magnesium Alloy Slabs
}

\author{
Shi Shuyan, Hao Hai, Zhang Xingguo, Fang Canfeng, Yao Shan, Jin Junze
}

State key Laboratory of Materials Surface Modification by Laser, Ion and Electronic Beams, Dalian University of Technology, Dalian 116024, China

\begin{abstract}
A mathematical model of the direct chill (DC) casting process for superlight Mg-Li alloy (LA141) slab has been developed using the finite differential method (FDM). Thermal boundary conditions including primary and secondary cooling conditions, have been selected based on knowledges of the physical process and the literatures. The variations of heat transfer coefficient between slab and dummy block interface resulting from the deformation of the slab have been considered. By calculating the temperature distribution, solid-liquid interface shape and position, the influence of casting parameters on DC casting process, such as the pour temperature, cooling water flow rate and casting speed have been analyzed. Moreover the profiles of the solidification fronts during the casting processes for the alloys of LA141 and AZ31 are compared.
\end{abstract}

Key words: superlight magnesium alloys; direct chill casting; slabs; temperature field; mathematical model

At the present time, with energy crisis and attention of environment protection, light-weight and recyclable materials are eagerly to be demanded. As the lightest alloys among the known metals and alloys, Mg-Li alloys (the density between 1300 and $1600 \mathrm{~kg} / \mathrm{m}^{3}$ ) have high specific stiffness and excellent ductility at low temperatures. So they have been attractively investigated and have the application potential in the fields of aerospace, aircraft structures, automobile and electric industry as well as for structural components in ultra-light communication systems ${ }^{[1-4]}$.

By addition of lithium into magnesium, not only the lightest alloy Mg-Li alloy can be obtained, offering density comparable to engineering plastics, but also the change of the crystal structure of the alloy will take place. At room temperature, Mg-Li alloys possess either $\alpha$ hexagonal close packed (hcp) structure (0-5wt\% Li) or $\beta$ body-centered cubic (bcc) structure (above $12 \mathrm{wt} \% \mathrm{Li}$ ) or $\alpha+\beta$ phases (5wt\%-12wt $\% \mathrm{Li}$ ). The previous literatures revealed that as increasing of $\mathrm{Li}$, the crystal lattice axes ratio, a/c, decreases through substitution of $\mathrm{Mg}$ atoms by Li atoms ${ }^{[5,6]}$. But binary Mg-Li alloys have the same problems such as the age hardening stability, low creep strength and poor corrosion resistance ${ }^{[6]}$. These problems would restrict their widespread applications. Further researches focus on the addition of a third even fourth element for forming Mg-Li- $x$ alloys for more widely application. The general mechanical properties of Mg-Li- $x$ alloys have been extensively investigated ${ }^{[7-10]}$. The commercial magnesium alloy, LA141, containing $14 \mathrm{wt} \% \mathrm{Li}$ and $1 \mathrm{wt} \% \mathrm{Al}$, has been considered for space applications, and it presents good mechanical properties ${ }^{[1]}$. However there is few reported work on the processing of Mg-Li alloys.

The direct chill (DC) casting process is widely used in the production of light-metal alloys and has been used in the casting of copper and steel. The process is attractive because of not only high production rates, but also producing a fine and uniform grain size at the fast freezing rates ${ }^{[11]}$. DC casting of nonferrous metals is characterized by high thermal conductivity, low casting speed, and high heat removal below the mould.

Received date: $2008-01-27$

Foundation item: Supported by the Key Grant of Science \& Technology by the Ministry of Education of China (107031)

Biograhy: Shi Shuyan, Candidate for Master, School of Materials Science and Engineering, Dalian University of Technology, Dalian 116024, P. R. China, Tel: 0086-411-84709458

Copyright @ 2009, Northwest Institute for Nonferrous Metal Research. Published by Elsevier BV. All rights reserved 
There are several parameters influencing the quality of the slab such as mould length, slab size, pour temperature, distribution of the cooling water and the rate of casting ${ }^{[12]}$. Considering the high cost and flammability of lithium, the optimization of the casting process and the calculation of the temperature distribution are attractive.

The aim of this paper is to build a mathematical model of the DC casting process of MgLi alloy(LA141) slab using finite differential method (FDM). By calculating the temperature profile, the influence of casting parameters on the DC casting process was obtained to optimize the casting process.

\section{Mathematical modeling}

For better understanding of solidification and cooling in the DC casting process, a 3-dimensional rectangular thermal model was proposed. Governing the partial differential equation of heat transfer used for this 3-dimensional mathematical model to predict cooling and solidification of the slab is shown in Equation (1):

$$
\frac{\partial}{\partial x}\left(k(T) \frac{\partial T}{\partial x}\right)+\frac{\partial}{\partial y}\left(k(T) \frac{\partial}{\partial y}\right)+\frac{\partial}{\partial z}\left(k(T) \frac{\partial}{\partial z}\right)+Q=\rho c_{\mathrm{p}}(T) \frac{\partial T}{\partial t}
$$

where $T$ is the temperature $(\mathrm{K}), k$ is the thermal conductivity $(\mathrm{W} /(\mathrm{m} \cdot \mathrm{K})), \rho$ is the density $\left(\mathrm{kg} / \mathrm{m}^{3}\right), c_{\mathrm{p}}$ is the specific heat $(\mathrm{J} /(\mathrm{kg} \cdot \mathrm{K}))$, and $t$ is time $(\mathrm{s})$. The latent heat release that occurs during the solidification should be taken into account, and $Q$ is a volumetric source term associated with the latent heat of solidification $\left(\mathrm{W} / \mathrm{m}^{3}\right) . x, y$ and $z$ are the rectangular coordinates.

\subsection{Calculation domain}

Cross section of the slab was $200 \mathrm{~mm} \times 400 \mathrm{~mm}$, the slab and dummy block was $500 \mathrm{~mm}$ and $100 \mathrm{~mm}$ in height, respectively. The model was set up based on the calculations for a $1 / 4$ section of the slab, because symmetry is assumed across the two mid planes in a transverse slice of the slab. The slab and dummy block were divided into many cubic elements (as shown in Fig.1). The total numbers of these elements in slab and dummy block were 40000 and 16000 , respectively.

\subsection{Initial conditions}

Initially, the dummy block and the mould were assumed to be of a uniform temperature equal to the cooling water temperature. The slab temperature was also assumed to be uniform and set to the pour temperature of the metal.

\subsection{Boundary conditions}

An important process input to the model is the heat transfer boundary conditions which was represented by the heat transfer coefficient. The formulation and parameters selected for the various boundary conditions necessary to describe the DC casting process were chosen from the literature. The specific boundary conditions formulated in the model are as follows:

1) Primary cooling: Primary cooling refers to the region where the slab or dummy block is within the mould at a given time. Equation (2) expresses these boundary conditions:

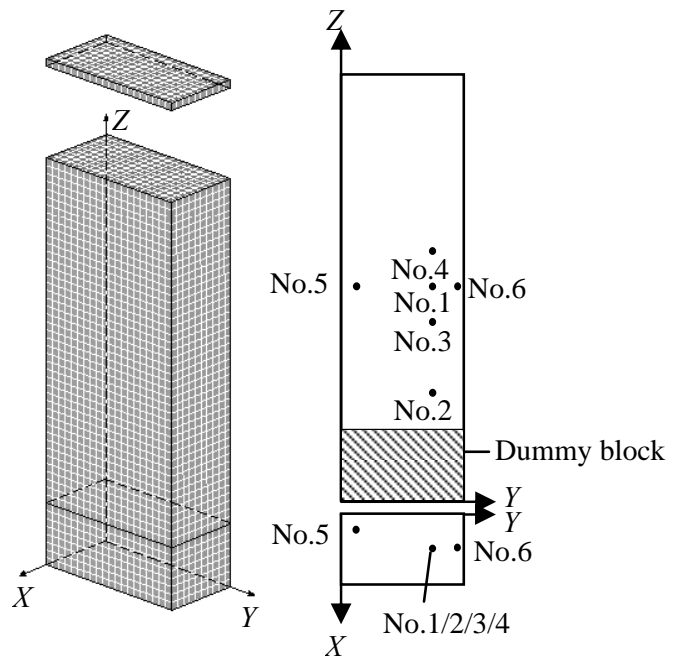

Fig.1 Schematic of the DC casting process calculation domain and calculated dot distribution

$$
-\left.k \frac{\partial T}{\partial x(y)}\right|_{x=X(y=Y)}=h_{\mathrm{eff}}\left(T_{\mathrm{s}}-T_{\mathrm{amb}}\right)
$$

where $h_{\text {eff }}$ is an effective heat transfer coefficient, which is a function of temperature; $T_{\mathrm{s}}$ is the surface temperature of the slab or dummy block; $T_{\mathrm{amb}}$ is the temperature of the mould. The temperature of mould is assumed to be invariable and equal to the cooling water temperature. The effective heat transfer coefficient embodies heat transfer process including interface contact, radiation, or conduction across a physical gap formed between the slab and the mould due to macro-deformation of the slab during metal solidification ${ }^{[12]}$.

2) Secondary cooling: Secondary cooling refers to the area below the mould that is in contact with water and is comprised of two regions: the impingement zone and the free falling zone. The impingement zone encompassed a region of 5-10 $\mathrm{mm}$ below the mould. The relationships to describe the heat transfer coefficient during secondary cooling were based on idealized boiling water curves ${ }^{[12]}$. Equation (2) was also used to describe these boundary conditions, but $T_{\mathrm{amb}}$ is cooling water temperature and is set to $25^{\circ} \mathrm{C}$.

3) Slab/dummy block interface ${ }^{[12]}$ : Equation (3) describes the flow of heat from the slab to the dummy block across the interface.

$$
-\left.k \frac{\partial T}{\partial z}\right|_{z=Z m}=h_{\text {eff,i }}\left(T_{\text {slab }}-T_{\text {dummyblock }}\right)
$$

In this interface, contact cooling to the dummy block $h_{\text {contact }}$ and radiation cooling to the air gap $h_{\text {rad }}$ was applied. In Equation (3), $h_{\text {eff,i }}$ is the effective interfacial heat transfer coefficient including $h_{\text {contact }}$ and $h_{\text {rad }}, T_{\text {slab }}$ is the slab surface temperature, and $T_{\text {dummyblock }}$ is the dummy block surface temperature. An air gap will form when the cooling water starts to impinge on the slab, so the effective interfacial heat transfer coefficient $h_{\text {eff,i }}$ 
would be changed by the deformation of the slab, and the parameter $f$, the fraction contact, is used to describe $h_{\mathrm{eff}, \mathrm{i}}{ }^{[12]}$.

4) Other boundary conditions: In the model the liquid metal were assumed to be added to the calculation domain by layers of elements to simulate the continuously pouring during the DC casting process. The rate at which new layers were added corresponded to the casting speed. Because of the continuous feed of new melt, it was assumed that there was an adiabatic condition on the top of the slab. The elements on the centerlines of the slab were also assumed to have no heat loss because of the symmetry. These boundary conditions are given in Equation (4):

$$
\begin{aligned}
& -\left.k \frac{\partial T}{\partial x, y, z}\right|_{x=0, y=0, z=Z(t)}=0 \\
& -\left.k \frac{\partial T}{\partial z}\right|_{z=0}=h_{\text {conv }}\left(T_{\text {surf }}-T_{\text {amb }}\right)
\end{aligned}
$$

Natural convection and radiation to the environment are considered along the bottom face of the dummy block. But in order to simplify the model, the radiation to the environment was assumed to be ignored because the temperature of dummy block is relatively low. Equation (5) describes the flow of heat from the bottom of the dummy block. Here $h_{\text {conv }}$ is the convective heat transfer coefficient to air and is set to $30 \mathrm{~W} /\left(\mathrm{m}^{2} \cdot \mathrm{K}\right)^{[12]}$, $T_{\text {surf }}$ is the surface temperature of the dummy block, and $T_{\mathrm{amb}}$ is the ambient air temperature and is set to $25^{\circ} \mathrm{C}$.

Before calculating the temperature distribution of LA141 slab during the DC casting process, the model should be validated firstly. The data used for validating the model come from J. M. Drezet ${ }^{[13]}$. The nominal slab cross section of aluminum alloy AA1201 was $1860 \mathrm{~mm} \times 510 \mathrm{~mm}$, and the height of the mould was $75 \mathrm{~mm}$. The casting parameters are shown as follows: the casting speeds were $50,60,80 \mathrm{~mm} / \mathrm{min}$, the cooling water flow rate was $800 \mathrm{~L} / \mathrm{min}$, and the pour temperature was $700-720^{\circ} \mathrm{C}$.

The calculation domain was also a $1 / 4$ section of the slab, and the thermal conductivity and specific heat were formulated to vary as a function of the local surface temperature. Despite the thermal conductivity of liquid aluminum being low (about $80-90 \mathrm{~W} /(\mathrm{m} \cdot \mathrm{K})$ ), the value of the thermal conductivity in this phase was increased to $300-400 \mathrm{~W} /(\mathrm{m} \cdot \mathrm{K})$ in the numerical computations because of account for liquid convection in the sump.

After a nearly steady state regime was obtained, five thermocouples were immersed from the top of the melt pool at various distances from the lateral surface of the slab in the midplane of a DC cast aluminum slab, and one of these was placed at the center line of the slab. The measured (continuous lines) and calculated (dash lines) temperature profiles along five vertical lines within an AA1201 slab of DC casting at 80 $\mathrm{mm} / \mathrm{min}$ are shown in Fig. 2. As can be seen, the agreement of the calculated with the measured (continuous lines) is fairly good. Therefore, the model can be used for calculating the

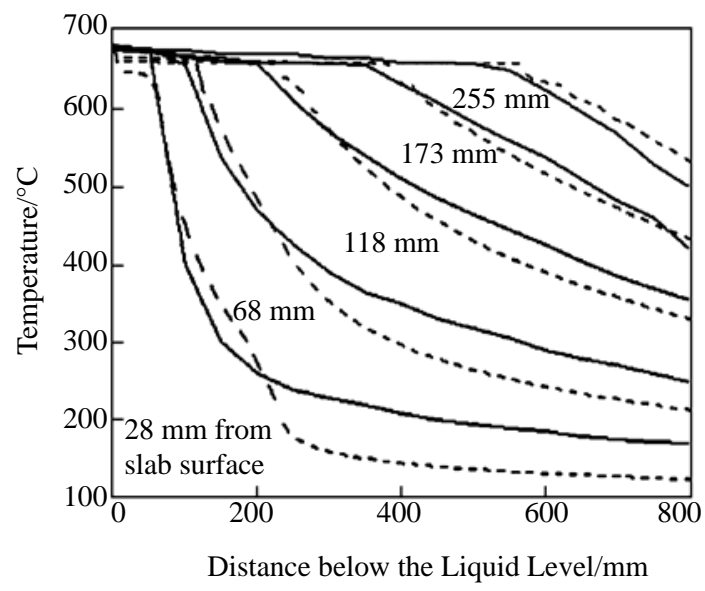

Fig.2 Measured (continuous lines) and calculated (dash lines) temperature profiles along five vertical lines within an AA1202 slab, DC cast at $80 \mathrm{~mm} / \mathrm{min}$

LA141 alloy slabs of DC casting, and the results could be used to optimize the casting parameters of DC casting.

\subsection{Casting parameters and thermophysical proper- ties of LA141}

As known, the casting speed is ramped during the start-up phase and then holds constant during steady-state. In this model the casting speed was assumed to be constant during the whole DC casting process. The slab was LA141 (Mg-14 pct Li-1 pct Al), and the dummy block was an aluminum alloy AA6061. The thermophysical properties for each of these materials included thermal conductivity, specific heat, latent heat and density. These values are given in Table 1 . And the liquidus and solidus temperatures of LA141 are $586{ }^{\circ} \mathrm{C}$ and 450 ${ }^{\circ} \mathrm{C}$, respectively, and the density of LA141 is $1350 \mathrm{~kg} / \mathrm{m}^{3[14]}$. Thermal conductivity and latent heat of LA141 are provided by ESI group and from literatures.

Table 1 Thermophysical properties used in the model

\begin{tabular}{ccccc}
\hline \multirow{2}{*}{ Material } & \multicolumn{2}{c}{ Thermal conductivity } & $\begin{array}{c}\text { Specific } \\
\text { heat }\end{array}$ & Latent heat \\
& & & & \\
& $T /{ }^{\circ} \mathrm{C}$ & $K / \mathrm{W} \cdot(\mathrm{m} \cdot \mathrm{k})^{-1}$ & $C_{\mathrm{p}} / \mathrm{J} \cdot(\mathrm{kg} \cdot \mathrm{K})^{-1}$ & $\mathrm{~L} / \mathrm{kJ}^{-} \mathrm{kg}^{-1}$ \\
\hline & 40 & 144.66 & & \\
& 430 & 148.70 & & \\
& 451 & 139.84 & & \\
LA141 $^{*}$ & 517 & 129.95 & $1449^{[14]}$ & \\
& 553 & 115.37 & & \\
& 590 & 83.05 & \\
AA6061 $^{[12]}$ & 20 & 180.0 & 896 \\
\hline
\end{tabular}




\section{Results and discussion}

In this work, the pour temperature, casting speed and cooling water flow rate were altered to assess the influence of each parameter on the distributing of the temperature. Fig.3 presents the comparison of predicted temperatures of location No.1 ( $x=52.5 \mathrm{~mm} ; y=152.5 \mathrm{~mm} ; z=302.5 \mathrm{~mm}$ ) for three different casting speeds (water flow rate is $1.0 \mathrm{~m}^{3} / \mathrm{h}$ and pour temperature is $720^{\circ} \mathrm{C}$ ).

Decreasing of casting speed will extend the time spent in the mould cooling zone (primary cooling). In the primary cooling zone, the faster the casting speed increased, the higher the temperature was, but it was exactly opposite in the secondary zone. Because by increasing casting speed, more molten metal would be poured into the mould and it spent little time in the mould, the temperature in the primary zone was higher. On the other hand, with more time spent in the secondary zone, the temperature in the secondary zone was lower.

As shown in Fig.4 and Fig.5 (the predicted temperature evolution of the location No.1), the comparison of the cooling water rate and the pour temperature have no obvious impact on the temperature at this location during solidification process. When the cooling water flow rate increased, the temperature decreased. The impact of increasing of the pour temperature in the primary zone was greater than that in the secondary zone. High pour temperature could receive good fluidity but have a bad influence on grain refining.

Temperatures of three nodes which had the same $x, y$ coordinate values ( $x=52.5 \mathrm{~mm} ; y=152.5 \mathrm{~mm}$ ) and different $z$ coordinate values (No.2, No.3 and No.4) were also calculated during the solidification process. The temperature profiles are shown in Fig. 6 and it can be seen that nodes near the dummy block have a larger solidification rate. It indicated that the cooling ability of the dummy block is limited at the locations far away to the slab bottom, and most heat is transferred by convection with cooling water in secondary cooling zone.

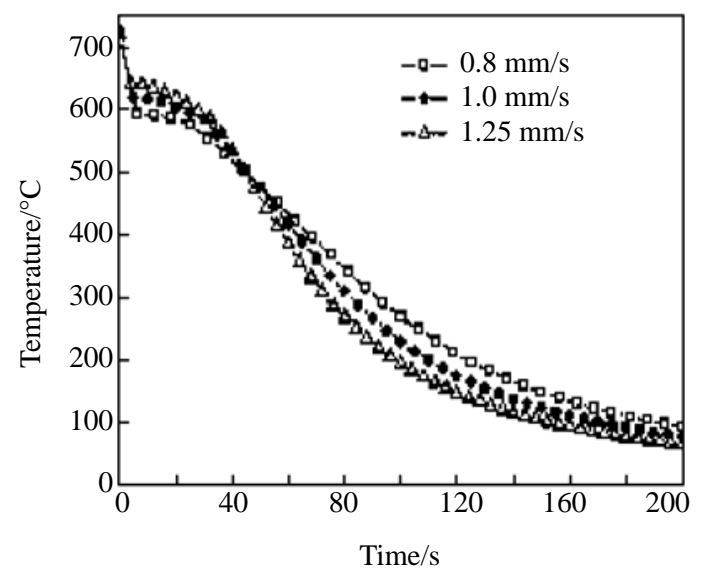

Fig.3 Comparison of predicted temperatures at location No.1 of Fig.1 for different casting speeds at the same cooling water flow rate and pour temperature

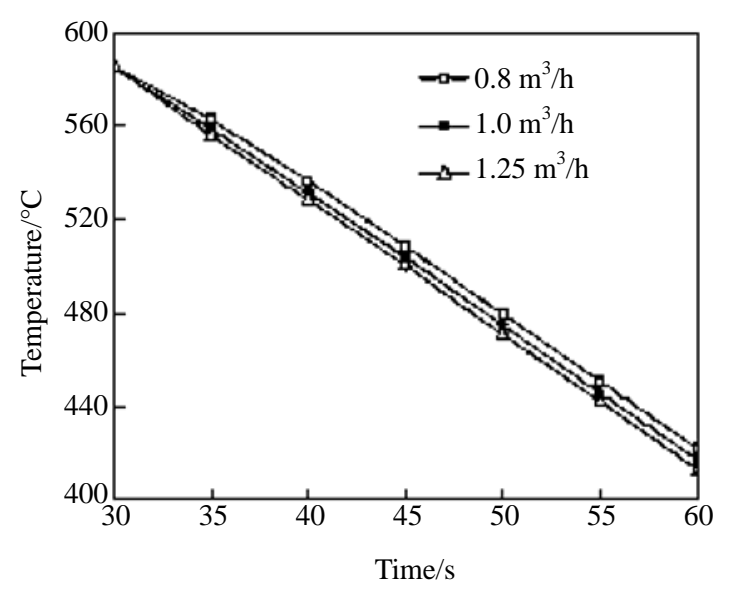

Fig.4 Comparison of predicted temperatures at location No.1 of Fig.1 for different cooling water flow rates at the same casting speed and pour temperature

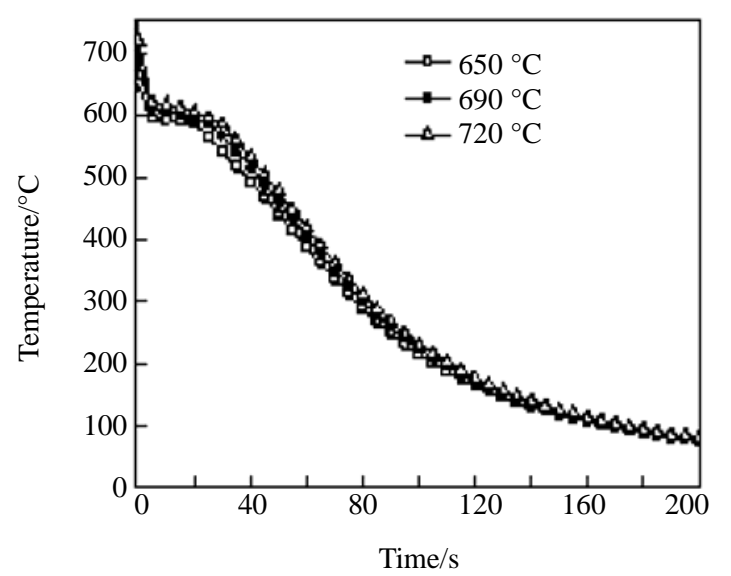

Fig.5 Comparison of predicted temperatures at location No.1 of Fig.1 for different pour temperatures at the same casting speed and cooling water flow rate

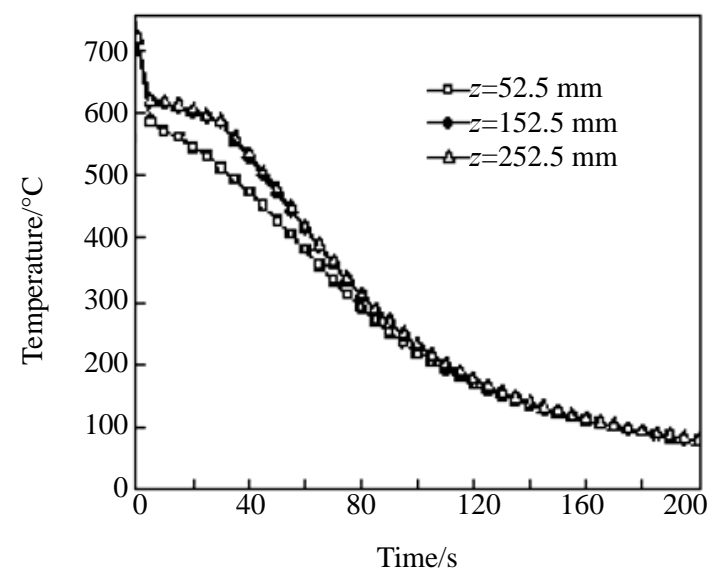

Fig.6 Comparison of predicted temperatures at location No.2, No.3 and No. 4 in Fig.1 for different heights from the surface of the dummy block 
Fig.7 shows the predicted steady-state sump profile of LA141 and AZ31 with three different casting speeds on YZ section. As can be seen, the predicted shell thickness and the sump depth decrease with increasing of casting speed. In order to avoid a dangerous breakout, the upper limit of casting speed should be examined. Fig. 8 shows the predicted temperature profiles of location No.5 (slab center: $x=27.5 \mathrm{~mm} ; y=27.5 \mathrm{~mm}$; $z=302.5 \mathrm{~mm}$ ) and location No.6 (slab edge: $x=52.5 \mathrm{~mm}$; $y=192.5 \mathrm{~mm} ; z=302.5 \mathrm{~mm}$ ) for two different materials (LA141 and AZ31) with the same casting parameters (casting speed is $1.0 \mathrm{~mm} / \mathrm{s}$, cooling water flow rate is $1.0 \mathrm{~m}^{3} / \mathrm{h}$ and pour temperature is $720^{\circ} \mathrm{C}$ ). It can be seen in Fig.8, at the same time, the temperature of LA141 is lower than that of AZ31, and the temperature difference of LA141 between the center and the edge is lower than that of AZ31. In other words, the solidification velocity of LA141 is larger than that of AZ31, and under the same casting conditions, the temperature distribution in LA141 slab is well-proportioned. The reasons may be as follows: the thermal conductivity of LA141 is larger than that of

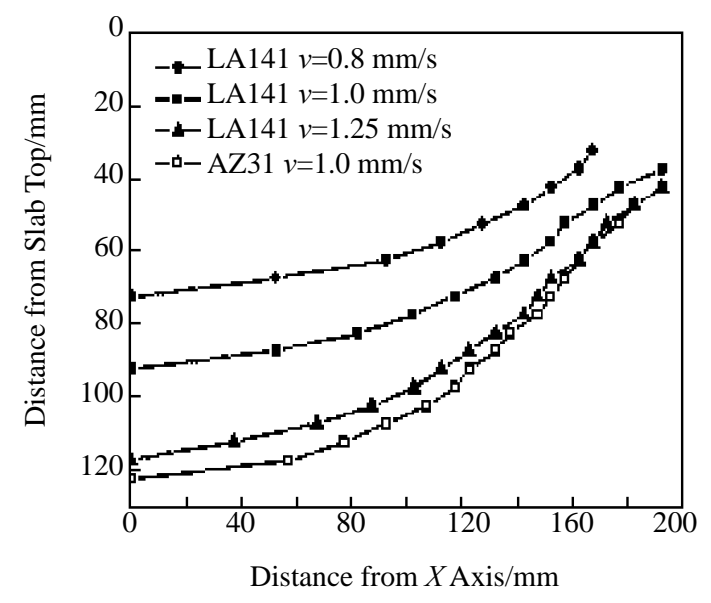

Fig.7 Predicted sump profiles of LA141 and AZ31 with three casting speeds on $Y Z$ section

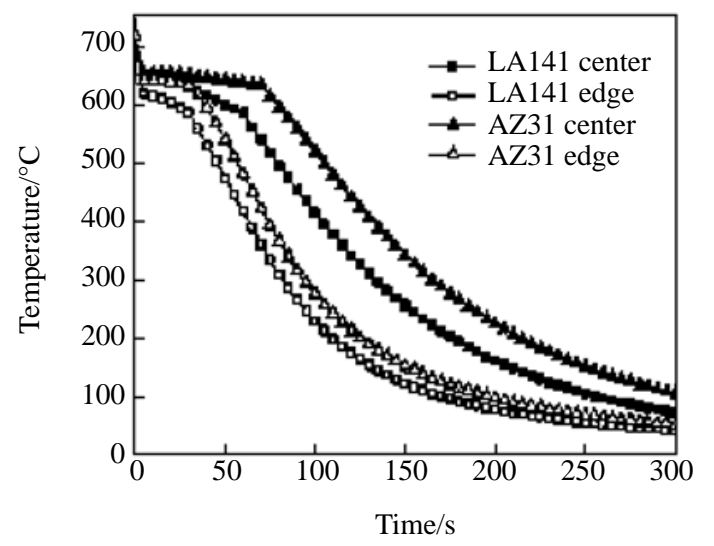

Fig.8 Comparison of predicted temperatures at location No.5 and No.6 of LA141 and AZ31 at the same casting speed, pour temperature and cooling water flow rate
AZ31, but the density of LA141 $\left(1350 \mathrm{~kg} / \mathrm{m}^{3}\right)$ is lower than that of AZ31 (1780 kg/m $\left.{ }^{3}\right)$; moreover the latent heat of LA141 (212 $\mathrm{kJ} / \mathrm{kg}$ ) is lower than that of AZ31 (339 kJ/kg $\left.{ }^{[12]}\right)$. As the same reasons, when casting speed is $1.0 \mathrm{~mm} / \mathrm{s}$ the sump depth of AZ31 is deeper than that of LA141 (shown in Fig.7). Well-proportioned temperature distribution in slabs could reduce the tendency of hot tearing. During DC casting process, the casting speed of LA141 slab could be faster than that of AZ31 and cooling water flow rate of LA141 slab can be decreased.

\section{Conclusions}

1) The impact of the pour temperature and cooling water flow rate on the temperature profile is limited, but the casting speed is more important for the DC casting process.

2) The cooling ability of impingement zone is better than that of free falling zone, and the cooling ability of the dummy block is the weakest.

3) At the same casting parameters, the solidification velocity of LA141 is larger than that of AZ31, and the sump depth of LA141 is lower than that of AZ31.

4) Comparing with AZ31 alloy, the casting speed can be faster, and the cooling water flow rate can be reduced during DC casting process.

\section{References}

1 Wei X W, Zu X T, Zhou W L. Materials Science and Technology[J], 2006, 22(6): 730

2 Cao F R, Cui J Z, Wen J L et al. Journal of Materials Science Technology[J], 2000, 16(1): 55

3 Sanschagrin A, Tremblay R, Angers R et al. Materials Science and Engineering $A[\mathrm{~J}]$, 1996, 220: 69

4 Haferkamp H, Boehm R, Holzkamp U et al. Materials Transactions[J], 2001, 42(7):1160

5 Tang W, Xu Y B, Han E H. Materials Science Forum[J], 2005, 488-489: 531

6 Lin M C, Uan J Y. Materials Transactions[J], 2005, 46(6): 1354

7 Song G S, Staiger M, Kral M. Materials Science and Engineering $A[\mathrm{~J}], 2004,371: 371$

8 Trojanová Z, Drozd Z, Lukác P et al. Materials Science and Engineering $A[\mathrm{~J}], 2005$, 410-411: 148

9 Chen B, Feng L P, Zhou T T et al. Materials Science Forum[J], 2005, 488-489: 155

10 Rudajevová A, Jäger A. Materials Science and Technology[J], 2005, 21(4): 433

11 Adenis D J P, Coats K H, Ragone D V. Journal of the Institute of Metals[J], 1962, 91: 395

12 Hao H, Maijer D M, Wells M A et al. Metallurgical and Materials Transactions $A[\mathrm{~J}], 2004,35 \mathrm{~A}: 3843$

13 Drezet J M, Rappaz B, Carrupt B et al. Metallurgical and Materials Transactions $B[\mathrm{~J}], 1995,26 \mathrm{~B}: 821$

14 Chen Zhenhua(陈振华). Magnesium Alloys(金属合金)[M]. Beijing: Chemistry Industry Press, 2004: 50 


\title{
超轻镁合金板坏直冷连铸三维温度场数值模拟
}

\author{
史淑艳, 郝 海, 张兴国, 房灿峰, 姚 山, 金俊泽 \\ (大连理工大学 三束材料改性国家重点实验室，辽宁 大连 116024)
}

\begin{abstract}
摘 要: 运用有限差分法, 对超轻 Mg-Li 合金（LA141）板坏直冷连铸过程温度场进行数值模拟，根据实际过程的物理现象以及文献资 料确定包括一冷区、二冷区在内的边界条件, 并且考虑底模与铸坏之间随着铸坏的变形而引起的换热系数的变化。通过计算铸坏内温度 场的分布, 固-液界面的形状和位置, 分析各种铸造参数, 包括浇注温度、冷却水量、铸造速度等对连铸过程的影响。另外也比较了在 同等铸造条件下 LA141 铸坏和 AZ31 铸坏铸造过程中凝固前沿的形状。
\end{abstract}

关键词: 超轻镁合金; 直冷连铸; 板坏; 温度场; 数学模型

作者简介: 史淑艳, 女, 1983 年生, 硕士生, 大连理工大学材料科学与工程学院, 辽宁 大连 116024, 电话: 0411-84709458 